\title{
1D Coordination m-d Conjugated Polymers with Distinct Structures Defined by the Choice of the Transition Metal: Towards a New Class of Antiaromatic Macrocycles
}

\author{
Vijai M. Santhini ${ }^{[a, b,+]}$, Christian Wäckerlin ${ }^{[a, c, t]}$, Aleš Cahlík ${ }^{[a, b, d, t]}$, Martin Ondráček ${ }^{[a]}$, Simon Pascal[e], \\ Adam Matěj ${ }^{[a, b]}$, Oleksandr Stetsovych ${ }^{[a]}$, Pingo Mutombo ${ }^{[a, f]}$, Petr Lazar ${ }^{[b]}$, Olivier Siri ${ }^{[e]}$, Pavel \\ Jelínek $^{*[a, b]}$
}
[a] Vijai M. Santhini, Dr. Christian Wackerlin, Aleš Cahlík, Dr. Martin Ondráček, Adam Matěj, Dr. Oleksandr Stetsovych, Dr. Pingo Mutombo, Dr. Pavel Jelínek Institute of Physics, Czech Academy of Sciences, Cukrovarnická 10,16200 Prague, Czech Republic. E-mail: jelinekp@fzu.cz
[b] Vijai M. Santhini, Aleš Cahlík, Adam Matěj, Dr. Petr Lazar, Dr. Pavel Jelínek Regional Centre of Advanced Technologies and Materials, Palacký University, Šlechtitelů 27, 78371 Olomouc, Czech Republic E-mail: jelinekp@fzu.cz
[c] Dr. Christian Wäckerlin
Surface Science and Coating Technologies, Empa, Swiss Federal Laboratories for Materials Science and Technology, Überlandstrasse 129,8600 Dübendorf, Switzerland
[d] Aleš Cahlík
Faculty of Nuclear Sciences and Physical Engineering, Czech Technical University in Prague,
Břehová 78/7, CZ-11519 Prague 1, Czech Republic
[e] Dr. Simon Pascal, Dr. Olivier Siri
Aix Marseille Université, CINaM UMR 7325 CNRS, Campus de Luminy 13288 Marseille cedex 09, France.
Dr. Pingo Mutombo
Department of Petrochemistry and Refining, University of Kinshasa,
Kinshasa, Democratic Republic of Congo
[t] These authors contributed equally to this work.
Corresponding Author

Abstract: Recently $\pi$-d conjugated coordination polymers have received a lot of attention due to their unique material properties, although synthesis of long and defect free polymers remains challenging. Here we introduce a novel on-surface synthesis of coordination polymers with quinoidal ligand under ultra-high vacuum conditions, which enables formation of flexible coordination polymers with lengths up to hundreds of nanometers. Moreover, this procedure allows the incorporation of different transition metal atoms tuning their coordination between four and two-fold. Remarkably, the two-fold coordination mode revealed the formation of wires constituted by (electronically) independent 12-membered antiaromatic macrocycles linked together through two C-C single bonds.

\section{Introduction}

One-dimensional (1D) covalent polymers are of considerable interest in many different technological sectors due to their unique electronic properties. ${ }^{[1-6]}$ The solvent-free synthesis of such nanomaterials at the surface has been emerging as a promising approach to obtain tailored low dimensional materials with atomic precision. Pure organic 1D materials can be obtained through catalyzed C-C coupling reactions on surface from halogenated precursors. ${ }^{[7-8]}$ Alternatively, 1D coordinationpolymers (CPs) can be isolated through coordination chemistry, the covalent bond formation resulting from on-surface reactions between metal atoms and suitable linker groups. ${ }^{[9-14]}$ One major advantage of this approach is the possibility to tune the properties of the wires by changing the nature of the metal and/or the ligand. In this strategy, the ligand design is crucia since maximizing the conjugation through coordination requires keeping the $\pi-d$ systems as coplanar as possible. Previous studies reported that low-lying $\pi^{*}$ orbitals of quinoidal ligands can mix extensively with the valence $d$-orbitals of a metal center, yielding complexes in which the electrons could be delocalized over both the metal and the ligand. ${ }^{[15-17]}$

In this context, 2,5-diamino-1,4-benzoquinonediimines (2HQDI) are particularly appealing because of their fascinating optical properties, ${ }^{[18-19]}$ and remarkable ability to serve as ligand in coordination chemistry. Unlike the N-substituted systems ( $\mathrm{N}$ alkyl or $\mathrm{N}$-aryl), ${ }^{[20-34]}$ the coordination chemistry of the parent (i.e. unsubstituted) molecule 2HQDI in solution has been poorly investigated probably due to its low solubility and specific reactivity that induced unwanted side-reactions. ${ }^{[35]}$ Some of us showed that the absence of $\mathrm{N}$-substituents (no steric hindrance) allows a unique behavior resulting from the stepwise formation of coplanar polynuclear complexes NiQDI with up to 3 repeat units $(n \leq 3)$ (Figure 1a). ${ }^{[17]}$ The oligomerization reaction proceeds in solution by successive deprotonation/metalation steps from 2HQDI, affording complexes in which each quinoid ligand is linked to two metal centers through two covalent and two coordinative bonds. As a result, the oxidation state of the metal centers is always $+\|$ and the $\pi$-system of the bridging unit is fully delocalized, forming $\pi-d$ delocalized systems. ${ }^{[36-41]}$ Importantly, the size of the oligomers depends on the nature of the solvent since the oligomerization process stops when the limit of solubility is attained. ${ }^{[42-43]}$ 
Herein, we explore the reaction between transition metal (TM) atoms $(\mathrm{Cr}, \mathrm{Fe}, \mathrm{Co}, \mathrm{Ni}$ and $\mathrm{Cu}$ ) and $\mathbf{2 H Q D I}$ directly at the solventfree solid surface under ultra-high vacuum conditions. We anticipated that this approach ${ }^{[44]}$ would overcome the limitations observed in solution and could lead to formation of extended flexible covalent coordination polymers with lengths of hundreds of nanometers. In the course of this study, we also observed a different coordination mode of the metal center to the ligand depending on the metal precursors and/or the nature of the substrate, see Figure 1b. More specifically, a new and remarkable coordination mode of the ligand 2HQDI was observed in the case of reaction with copper, resulting in the formation of wires based on unique (poly) macrocycles, see Figure $1 \mathrm{~b}\left(\mathrm{Cu}_{2} \mathbf{Q D I}\right)$. A combined experimental and theoretical study allowed us to resolve its chemical structure consisting of a 12-membered ring incorporating two copper centers. These macrocycles can be considered as a new class of antiaromatic compounds. ${ }^{[45-46]}$

\section{Results and Discussion}

The metals $\mathrm{Cr}$, Fe, $\mathrm{Co}$ and $\mathrm{Ni}$ are introduced as neutral metal atoms from an electron-beam evaporator while $\mathrm{Cu}$ is provided directly by the $\mathrm{Cu}$ substrate (as detailed in the Supplementary Information). The ligand precursor 2HQDI is deposited simultaneously by sublimation, and is let to react on $\mathrm{Cu}(111)$ and $\mathrm{Au}(111)$ surfaces with the metal atoms. With all metals, isolated 1D metal-organic coordination polymers are obtained. As we show, the $\{\mathrm{Cr}, \mathrm{Fe}, \mathrm{Co}, \mathrm{Ni}\}$ containing $\mathrm{CPs}$ are based on four-fold square-planar coordination where the metal atom is coordinated head-to-head between two ligands (MQDI in Figure 1b). Figure $1 \mathrm{c}($ top, middle) shows a representative highresolution nc-AFM image FeQDI/Au(111), recorded with $\mathrm{CO}$ functionalized tip ${ }^{[47,48]}$ revealing a characteristic " $x$-like" contrast feature in between the molecular units. On the contrary, Cu-CPs are based on two-fold linear coordination motifs where each $\mathrm{Cu}$ atom is linked to the nitrogen atoms of the ligand arranged sideby-side $\left(\mathbf{C u}_{2} \mathbf{Q D I}\right.$ in Figure $\left.1 \mathrm{~b}\right)$, as demonstrated by highresolution nc-AFM image of $\mathrm{Cu}_{2} \mathbf{Q D I}$ wire on $\mathrm{Cu}(111)$ (shown in Figure 1d top, middle) exhibiting a distinct structural contrast. Due to the different arrangement of the molecular building blocks, the periodicity of $\mathrm{Cu}_{2} \mathbf{Q D I}(6.8 \pm 0.1 \AA$, Figure S1) along the wire is also noticeably shorter compared to $7.7 \pm 0.1 \AA$ for FeQDI. Notably, FeQDI/Cu(111) exhibits a similar AFM contrast as FeQDI/Au(111) (Figure S1), featuring the characteristic "x-like" appearance on the $\mathrm{Fe}$.

To confirm the structures, we carried out total energy DFTB3LYP ${ }^{[50-51]}$ calculations of FeQDI/Au(111), FeQDI/Cu(111) and $\mathrm{Cu}_{2} \mathrm{QDI} / \mathrm{Cu}(111) 1 \mathrm{D}$ coordination polymers. The lattice vectors of the optimized DFT structures (Figure S2) are in very good agreement with the experimentally acquired values. Furthermore AFM simulations using the probe-particle model ${ }^{[52]}$ fully reproduce the experimental AFM contrast, see Figure 1c and 1d (bottom). N-N covalent bonding between the ligands can be firmly ruled out, as it would result in a shorter molecule-tomolecule periodicity (5.7 ̊̊ from DFT). (a) Previous works (in solution)

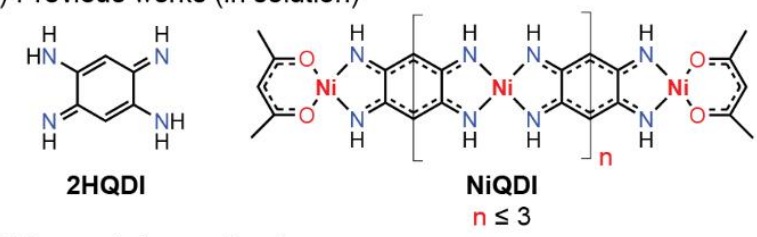

(b) Our work (on surface)
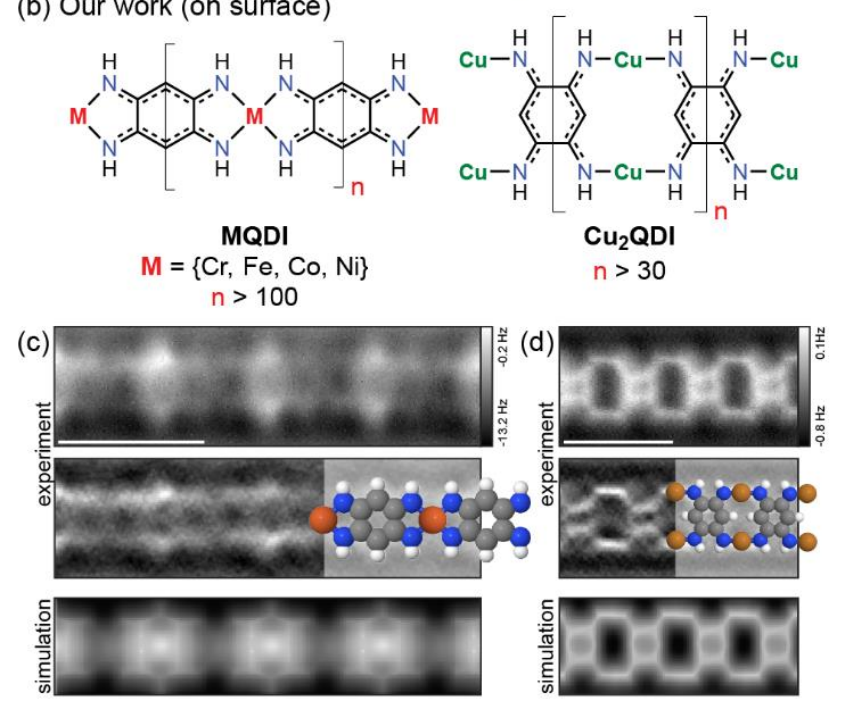

Figure 1: (a) Formation of coplanar polynuclear complexes NiQDI in solution (b) On surface formation of structurally distinct four-fold coordinated MQDI (M= $\mathrm{Cr}, \mathrm{Fe}, \mathrm{Co}, \mathrm{Ni})$ wires and two-fold coordinated $\mathrm{Cu}_{2} \mathbf{Q D I}$ wires by dehydrogenative metalation. (c, d) Top: High resolution constant height ncAFM images (scalebar $1 \mathrm{~nm}$ ) recorded with CO modified tip of FeQDI wire on $\mathrm{Au}(111)\left[\mathrm{V}_{\text {bias }}=1 \mathrm{mV}, \mathrm{A}_{\mathrm{osc}}=50 \mathrm{pm}\right]$ and $\mathrm{Cu}_{2} \mathbf{Q D I}$ wire on $\mathrm{Cu}(111)\left[\mathrm{V}_{\text {bias }}=1 \mathrm{mV}\right.$, $\left.A_{o s c}=50 \mathrm{pm}\right]$. Middle: High pass filtered version of the high-resolution images for better clarity superimposed with space filling models $(\mathrm{C}, \mathrm{H}, \mathrm{N}, \mathrm{Fe}$ and $\mathrm{Cu}$ atoms correspond to grey, white, blue, orange and brown colors respectively.) Bottom: Simulated AFM images of FeQDI/Au(111) and $\mathrm{Cu}_{2} \mathrm{QDI} / \mathrm{Cu}(111)$ coordination polymers.

The dehydrogenation reaction on the surface and simultaneous formation of metal coordinated wires is further supported by XPS measurements (Figure S3) of $\{\mathrm{Fe}, \mathrm{Ni}\} Q D I$ wires on $\mathrm{Au}(111)$ surface and $\mathrm{Cu}_{2} \mathrm{QDI}$ wires on $\mathrm{Cu}(111)$ surface. N1s XP spectra of native $2 \mathrm{HQDI}$ on both $\mathrm{Au}(111)$ and $\mathrm{Cu}(111)$ reveal two components, corresponding to $-\mathrm{NH}_{2}$ and $-\mathrm{NH}$ groups. In contrast, for the synthetized $\left\{\mathrm{Fe}, \mathrm{Ni}, \mathrm{Cu}_{2}\right\} \mathrm{QDI}$ wires, only one N1s component is observed, showing that all four nitrogen atoms of the ligand have identical chemical environments, consistent with the structures shown in Figure $1 \mathrm{~b}$. This also excludes the possibility of hydrogen-bonded wire growth.

For $\mathbf{C u}_{2} \mathbf{Q D I}$, we could identify 12-membered macrocycles involving twelve $\pi$ electrons of the ligand. The bridging QDI ligand can be indeed described as two nearly-independent six $\pi$ electrons subunits chemically connected through two C-C single bonds (the so-called "coupling principle") ${ }^{[49]}$. As a consequence, the $\mathrm{Cu}_{2} \mathbf{Q D I}$ wires are constituted of electronically independent macrocycles linked together through two $\mathrm{C}-\mathrm{C}$ single bonds, preventing a full delocalization over the wire. 


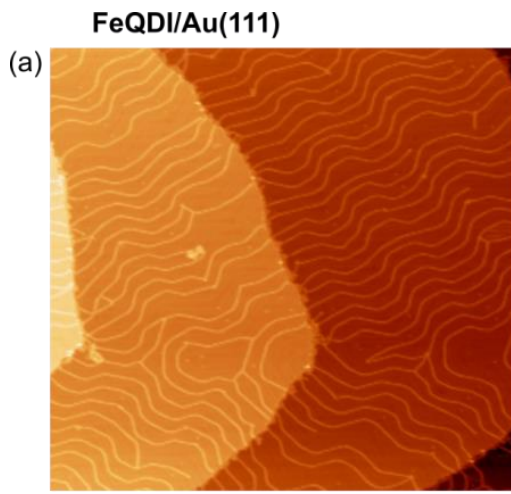

(d)

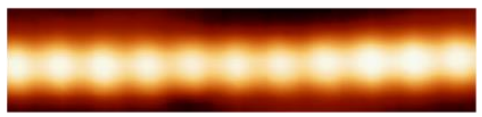

(g)

\section{CrQDI/Au(111)}

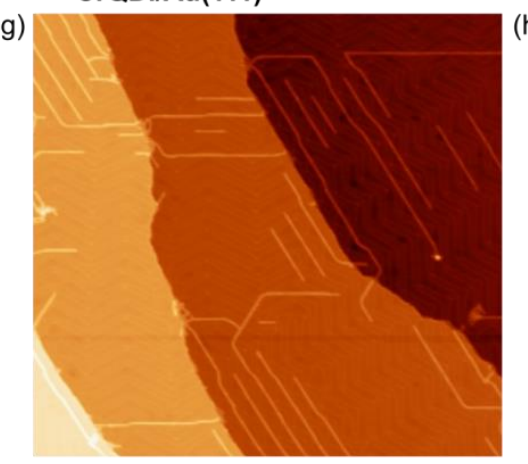

(j)

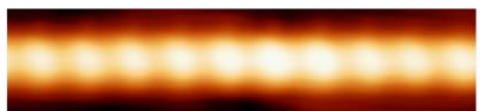

$\mathrm{Cu}_{2} \mathrm{QDI} / \mathrm{Cu}(111)$

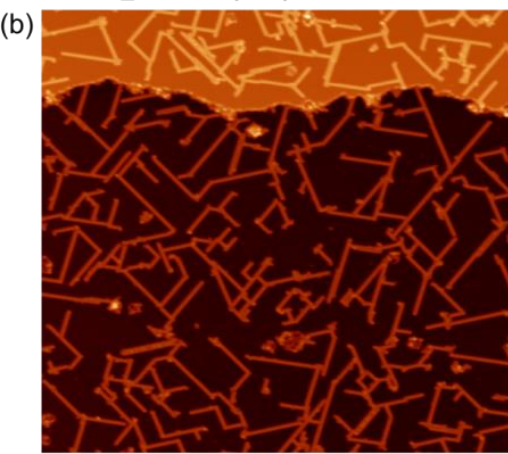

(e)

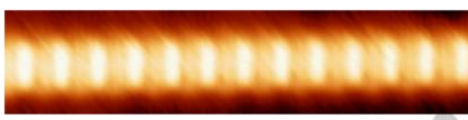

CoQDI/Au(111)

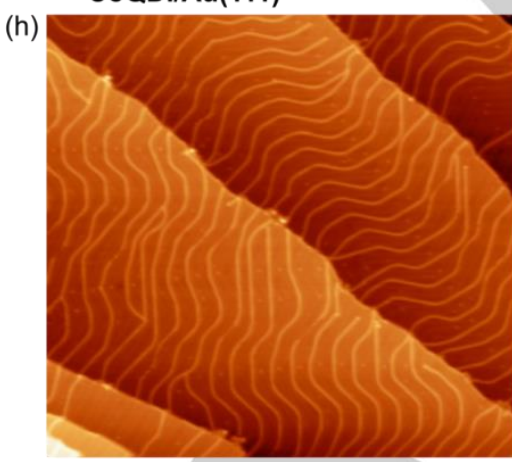

(k)

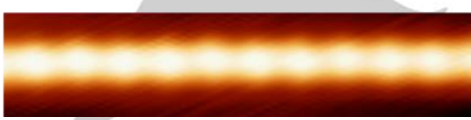

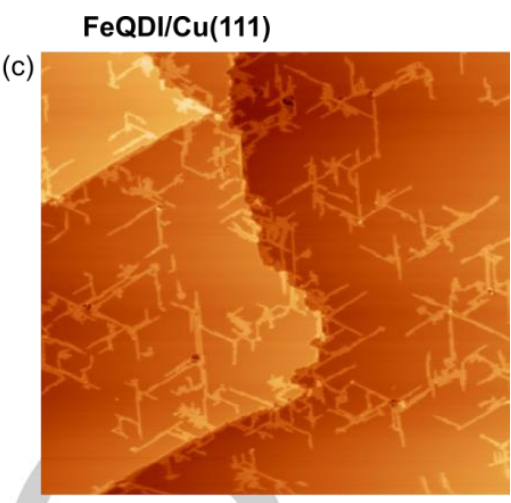

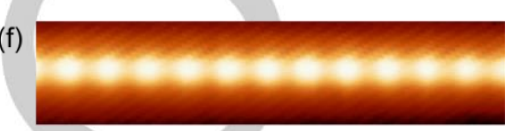

$\mathrm{NiQDI/Au(111)}$

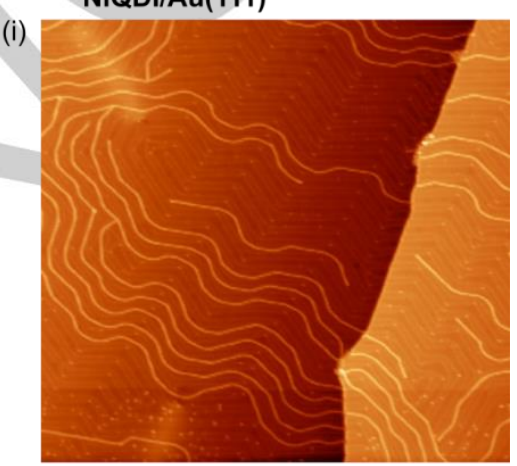

(I)

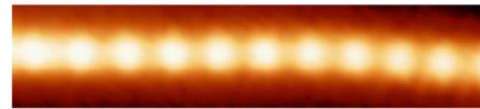

Figure 2: STM images of $\{\mathbf{C r}, \mathbf{F e}, \mathbf{C o}, \mathbf{N i}\} \mathbf{Q D I}$ wires on $\mathrm{Au}(111)$ and of $\mathbf{C u}_{2} \mathbf{Q D I}$ and $\mathbf{F e Q D I}$ wires on $\mathrm{Cu}(111)$. The overview images are $200 \times 200 \mathrm{~nm}^{2}$ and the zoom-in images are $8 \times 2 \mathrm{~nm}^{2}$. Imaging parameters (bias voltage, tunnel current set point): (a) (500 mV, $\left.10 \mathrm{pA}\right) ;$ (b) (1.2 V, $\left.10 \mathrm{pA}\right) ;(\mathrm{c})(500 \mathrm{mV}, 20 \mathrm{pA}) ;(\mathrm{d})(-200$ $\mathrm{mV}, 23 \mathrm{pA}) ;(\mathrm{e})(300 \mathrm{mV}, 30 \mathrm{pA})$; (f) (-200 mV, $50 \mathrm{pA}) ;(\mathrm{g})(100 \mathrm{mV}, 30 \mathrm{pA}) ;(\mathrm{h})(350 \mathrm{mV}, 10 \mathrm{pA}) ;$ (i) (100 mV, $42 \mathrm{pA}) ;$ (j) $(30 \mathrm{mV}, 10 \mathrm{pA}) ;(\mathrm{k})(-400 \mathrm{mV}, 32 \mathrm{pA}) ;(\mathrm{l})$ (100 mV, $42 \mathrm{pA})$.

Overview STM images of $\{\mathbf{C r}, \mathrm{Fe}, \mathrm{Co}, \mathrm{Ni}\} \mathrm{QDI}$ on $\mathrm{Au}(111)$, $\mathrm{Cu}_{2} \mathrm{QDI}$ on $\mathrm{Cu}(111)$ and $\mathrm{FeQDI}$ on $\mathrm{Cu}(111)$ are displayed in Figure 2. For $\mathbf{\{} \mathbf{C r}, \mathbf{F e}, \mathbf{C o}, \mathbf{N i}\} \mathbf{Q D I}$ on $\mathrm{Au}(111)$, very long regular wires easily exceeding lengths of $100 \mathrm{~nm}$ can be observed. On $\mathrm{Au}(111)$, the wires loosely follow the herringbone reconstruction of the substrate and can be easily manipulated by the STM tip and bent into manifold shapes (Figure S4). This points to their relatively weak interaction with the $\mathrm{Au}(111)$ substrate. In the zoom-in STM images (Figure 2), the $\mathrm{Cu}_{2} \mathbf{Q D I}$ wires appear significantly wider compared to the $\{\mathrm{Cr}, \mathrm{Fe}, \mathrm{Co}$ and Ni\}QDI ones and their periodicity along the wire is visibly smaller (in agreement with the nc-AFM observation). In combination with the known coordination geometry of FeQDI and $\mathbf{C u}_{2} \mathbf{Q D I}$ determined by nc-AFM (Figure 1c, d, Figure S1), these two properties show that $\{\mathrm{Cr}, \mathrm{Fe}, \mathrm{Co}, \mathrm{Ni}\} \mathbf{Q D I}$ on $\mathrm{Au}(111)$ and $\mathrm{FeQDI}$ on $\mathrm{Cu}(111)$ are essentially isostructural with square-planar bonding scheme. Most of the individual MQDI wires on $\mathrm{Au}(111)$ are truly one dimensional, although branching between two wires occasionally occurs. Compared to all MQDI wires on $\mathrm{Au}(111)$, both types of wires (FeQDI and the $\mathbf{C u}_{2} \mathbf{Q D I}$ ) branch more frequently on $\mathrm{Cu}(111)$ and they follow specific directions of the substrate. By analogy with the growth of organic and inorganic $2 \mathrm{D}$ materials at surfaces, ${ }^{\left[{ }^{[3-54]}\right.}$ the higher frequency of branching suggests that the growth on $\mathrm{Cu}(111)$ is more kinetically controlled. This can be attributed to higher diffusion barriers on $\mathrm{Cu}(111)$ as compared to $\mathrm{Au}(111)$.

Interestingly, while FeQDI can be prepared on either $\mathrm{Au}(111)$ or $\mathrm{Cu}(111)$, we have been unable to prepare $\mathrm{Cu}_{2} \mathbf{Q D I}$ wires on $\mathrm{Au}(111)$ by electron-beam evaporation of $\mathrm{Cu}$. We ascribe it to the preferential diffusion of $\mathrm{Cu}$ adatoms into the bulk of the $\mathrm{Au}$ single crystal.

To understand the origin of the different coordination mechanism of $\mathrm{Cu}$, we analyzed theoretically the formation energies using DFT calculations of free-standing polymers (for details see Figure S5). The FeQDI coordination polymer prefers energetically the 4-fold coordination, while the 2-fold coordination is favorable for $\mathbf{C u}_{2} \mathbf{Q D I}$ wire, in good agreement with the experimental observation. To get more insight into this trend, we also analyzed the electronic structure of the wires. Note, that our DFT B3LYP calculations reveal a closed-shell ground state of $\mathrm{Cu}_{2} \mathrm{QDI}$ chain, while in the case of FeQDI, the chain is open-shell with spin $S=1$. A detailed experimental and theoretical analysis of magnetic properties of MQDI chains is under investigation and it will be published as a separate scientific paper. 
Figures S6 and S7 show calculated projected density of states (PDOS) of free standing FeQDI and $\mathrm{Cu}_{2} \mathbf{Q D I}$ chains respectively. In the case of the FeQDI wire with its four-fold coordination, more $d$-orbitals are involved in the rehybridization with the $p_{z^{-}}$ orbitals of the ligand. Also, in the case of other TM atoms $(\mathrm{Cr}$, Co, Ni), partial filling of their $d$-orbitals promotes strong hybridization with the ligand field adopting the 4-fold coordination. ${ }^{[17,35]}$ In the case of the two-fold coordinated $\mathrm{Cu}_{2} \mathrm{QDI}$ chain, only $s$ and $d_{y z}$ orbitals hybridize with $\mathrm{p}_{z}$-orbitals of nitrogen atoms of the ligand. Since the fully occupied $d$-orbitals of $\mathrm{Cu}(\mathrm{I})$ are reluctant to be involved in the chemical bonding with ligands, the two-fold coordination and thus $\mathrm{Cu}_{2} \mathbf{Q D I}$ structure is preferred. $\mathrm{Cu}$ atoms can easily form complexes in $+\mathrm{l}$ oxidation state because they are then stabilized by their $3 d^{10}$ electronic configuration, unlike $\mathrm{Cr}, \mathrm{Fe}$, $\mathrm{Co}$ and $\mathrm{Ni}$ which prefer oxidation states of +ll or higher. The $\mathrm{Ni}_{2} \mathrm{p}_{3 / 2} \mathrm{XP}$ spectrum of $\mathrm{NiQDI} / \mathrm{Au}(111)$ (binding energy $854.5 \mathrm{eV}$ ) firmly supports a +ll oxidation state (Figure S3). ${ }^{[5]}$ In contrast, the Fe2p $3 / 2$ binding energy of $\mathrm{FeQDI} / \mathrm{Au}(111)(707.3 \mathrm{eV})$ is surprisingly low for a $\mathrm{Fe}$ (II) ion. The same effect, i.e. high $\mathrm{Ni}$ and low $\mathrm{Fe}$ binding energy, has been reported for $\{\mathrm{Fe}$, Ni\}porphyrins, phthalocyanines and related compounds ${ }^{[56]}$ and is interpreted as a partial shift of electron density from the substrate to the metal ion, in line with the original explanation of this effect. ${ }^{[57-59]}$ Unfortunately, because of the overwhelming substrate signals we cannot study $\mathrm{Cu} X P$ spectra of $\mathrm{Cu}_{2} \mathrm{QDI} / \mathrm{Cu}(111)$.

Indeed, the analysis of the electrostatic potential maps of FeQDI (Figure S8a) and $\mathrm{Cu}_{2} \mathbf{Q D I}$ (Figure S8b) (revealing the charge transfer from TMs to the QDI ligand) clearly show that the charge transfer is larger in the case of FeQDI, where Fe in fourfold coordination is typically found in +II oxidation state. Consequently, we conclude that $\mathrm{Cu}$ in the $\mathrm{Cu}_{2} \mathbf{Q D I}$ polymer is found in $+\mathrm{l}$ state. This observation is consistent with the coordination of the copper center through one covalent and one dative bond with the ligand enabling two isomeric electronic structures as shown on Figure 3a. This allows the delocalization of the $\pi-d$ electrons over the macrocycle, in contrast to the coordination exclusively through dative bonds as observed in supramolecular complexes. ${ }^{[60]}$

This picture is also supported by DFT calculations. Namely, the calculated band structure shows relatively strong dispersion of both valence and conduction bands resulting in the band width of $\sim 0.5-1 \mathrm{eV}$, see Figure S9a and S9b. Also, real space images of electron density of both the valence and conduction bands (Figure S9c and S9d) reveal a strong hybridization of $d$-orbitals with $p_{z}$-orbitals of nitrogen atoms on the ligand and delocalization of the electronic states over both TM and ligand. Moreover, the analysis of the bond lengths suggests that in both FeQDI (Figure S10a) and $\mathrm{Cu}_{2} \mathrm{QDI}$ (Figure S10b) wires, the $\pi$ system of the quinoidal ligand is strongly delocalized, as shown schematically in Figure $1 \mathrm{~b}$. All these findings strongly suggest that the presented $1 \mathrm{D}$ coordination polymers exhibit $\pi-d$ conjugation.

Next, we provide an analysis of the aromatic character of the macrocycle in the $1 \mathrm{D}$ chain $\mathbf{C u}_{2} \mathbf{Q D I}$. Figure 3 shows the bond scheme, calculated maps of the nucleus-independent chemical shift (NICS) ${ }^{[61]}$ and the anisotropy of the current induced density (ACID) ${ }^{[62]}$ for free-standing $\mathrm{Cu}_{2} \mathrm{QDI}$ chain. In the case of $\mathrm{Cu}_{2} \mathrm{QDI}$ chain, the positive NICS values (Figure 3b) with maxima over the $\mathrm{C}_{6}$ ring of the ligand and the 12-membered macrocycle of $+8.6 \mathrm{ppm}$ and $+6.6 \mathrm{ppm}$ respectively, indicate that both are antiaromatic in nature. Also the calculated ACID plot of $\mathbf{C u}_{2} \mathbf{Q D I}$ chain in Figure $3 \mathrm{c}$ reveals anticlockwise current density vectors exhibiting paratropic current and thus antiaromaticity, in agreement with the NICS data. Interestingly, the current density vectors of both the $\mathrm{C}_{6}$ ring of the ligand as well as the 12membered cycle are seen as separate loops, hence substantiating that the backbone of the $1 \mathrm{D} \mathbf{C u}_{2} \mathbf{Q D I}$ chain is formed by individual delocalized macrocycles as depicted schematically in Figure 3a. The antiaromatic character of the quinoidal ligand is also confirmed by a negative harmonic oscillator model of aromaticity (HOMA) value of -0.241 (see Supporting Information for HOMA calculations).
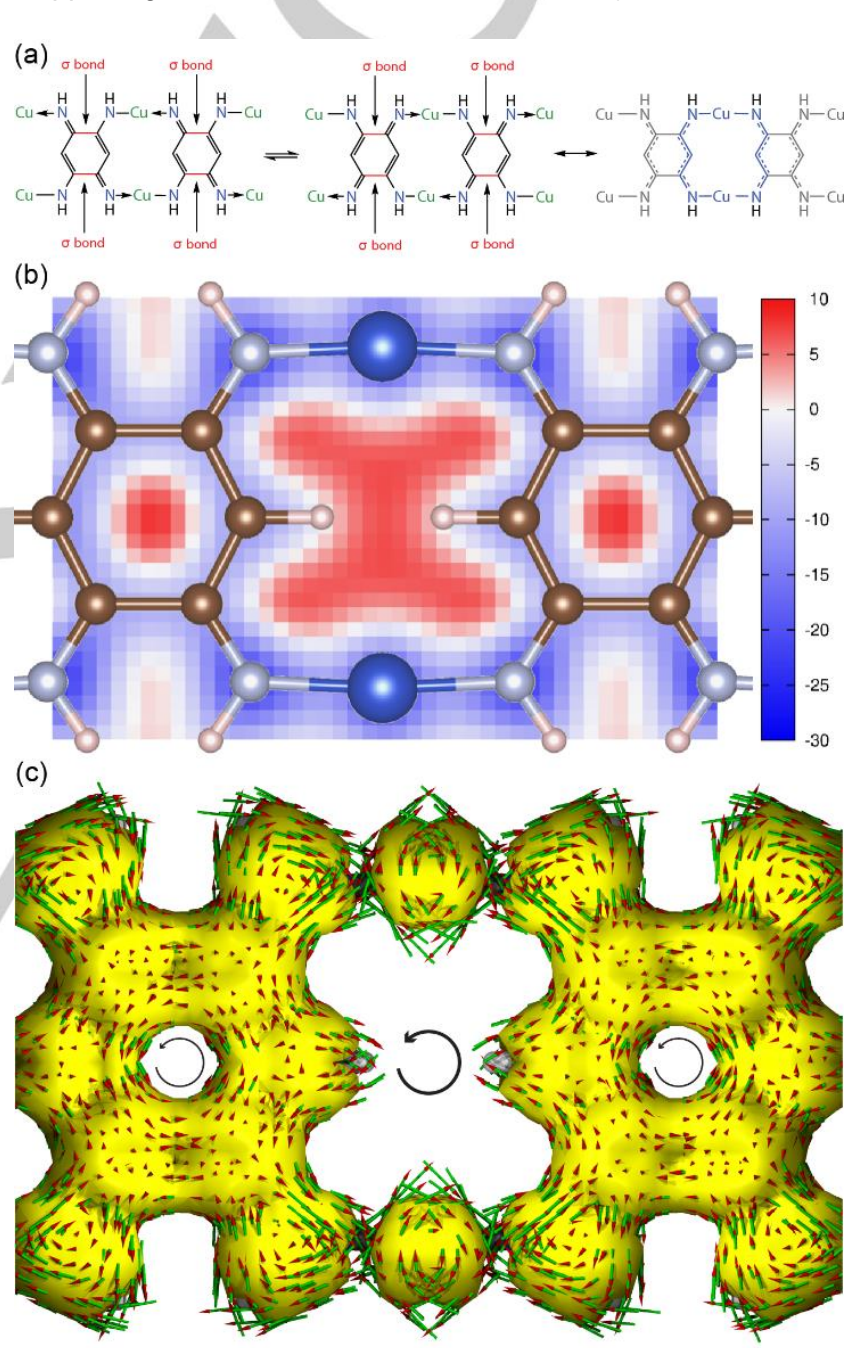

Figure 3: (a) Scheme depicting the bonds and resonating structures of the 12 membered macrocycle in $\mathbf{C u}_{2} \mathbf{Q D I}$ wires on $\mathrm{Cu}(111)$. (b) NICS grid of $\mathrm{Cu}_{2} \mathbf{Q D I} / \mathrm{Cu}(111)$. (c) $\mathrm{ACID}$ plot of $\mathrm{Cu}_{2} \mathrm{QDI} / \mathrm{Cu}(111)$, black arrow indicating the anticlockwise direction of current density vectors for better clarity. The molecular planes are placed perpendicular to the magnetic field vector. Small green arrows are computed current density vectors.

In order to understand the aromaticity of conjugated metallacycles, Mauksch and Tsogoeva have worked out the frontier $\pi$-orbital topology rule: "The metallacycle is aromatic 
(antiaromatic) when the number of $\pi-\mathrm{MOs}$ is even and the $\pi-$ $\mathrm{HOMO}$ is of Möbius (Hückel) topology-and vice versa when the number of $\pi-M O s$ is odd." [63] The nature of the aromatic stabilization in metallacycles related to the bonding between the transition metals and the adjacent atoms permits two different topologies of the $\pi-d$ orbital conjugation: Hückel and Mobius topology, where the latter involves the $d$-orbitals introducing a frustrated phase variation of $\pi$-orbitals in the metallacycle. ${ }^{[64]}$ The 12-membered macrocycle in the $\mathbf{C u}_{2} \mathbf{Q D I}$ chain consists of two $d_{y z}$ metal orbitals which change the phase of adjacent $\pi$ orbitals of $\mathrm{N}$ atom (see HOMO shown in Figure S9b). The presence of an even (two) number of $d$-orbitals causing the change of the phase in the cycle avoids the frustration of the $\pi$ orbital phase in the cycle. Consequently, the $\pi-d$ conjugation of the macrocycle can be considered as Hückel topology. The 12membered macrocycle in the $\mathbf{C u}_{2} \mathbf{Q D I}$ chain consists of $8 \pi-\mathrm{MOs}$ (even) and $\pi-\mathrm{HOMO}$ is of Hückel topology, thus the macrocycle is antiaromatic in nature following the Mauksch and Tsogoeva rule, in agreement with the ACID and NICS analysis. Noteworthy this rule is strictly applicable for the macrocycles whose number of $\pi$-electrons is equal to the number of members in the ring, as discussed recently. ${ }^{[65]}$

In the case of FeQDI, the NICS value (see Figure S11a) for the $\mathrm{C}_{6}$ ring of the ligand as well as the five membered ring containing the metal is negative (with maximal values of $-25.7 \mathrm{ppm}$ and $17.5 \mathrm{ppm}$ respectively) exhibiting aromatic character. The negative values of NICS is indicative of a diatropic ring current in presence of a magnetic field, which agrees with the calculated ACID isosurface for the FeQDI chain (see Figure S11b). Nevertheless, we should note that despite relatively large NICS numbers, the ACID plot reveals that the current density is not completely circular on the quinoidal ring. Instead, ACID confirms the existence of two decoupled delocalized $\pi-d$ electronic systems as schematically depicted in Figure $1 b$ for MQDI. This decoupling is also confirmed by a relatively large bond length alternation within the $\mathrm{C}_{6}$ ring of the ligand (Fig S10). Consequently, the harmonic oscillator model of aromaticity $(\mathrm{HOMA})^{[66]}$ value of the quinoidal ring is about 0.486 , predicting a weak aromatic character (for details of HOMA calculations see Supporting Information).

\section{Conclusion}

In conclusion, we presented a novel route to the synthesis of long and defect-free 1D coordination $\pi$-d conjugated polymers, achieved by co-deposition of the $2 \mathrm{HQDI}$ molecular precursor and various transition metal ( $\mathrm{Fe}, \mathrm{Co}, \mathrm{Ni}, \mathrm{Cr}, \mathrm{Cu}$ ) atoms on metal surfaces under UHV conditions. This approach overcomes the problem of solubility limiting traditional wet chemistry synthesis, and enables to grow up to hundreds of nanometers long defectfree covalent polymers. By high-resolution AFM imaging and theoretical calculations, we demonstrated that all TMs (except $\mathrm{Cu}$ ) adopt a four-fold coordination motif with nitrogen atoms of the QDI ligand (MQDI). In the case of $\mathrm{Cu}$ atoms, we found a new coordination mode of the ligand and the formation of the linear two-fold coordinated $\mathrm{Cu}_{2} \mathrm{QDI}$ polymer. Our analysis indicates that the electronic states of polymers MQDI $(\mathrm{M}=\mathrm{Fe}, \mathrm{Co}, \mathrm{Ni}, \mathrm{Cr})$ fully delocalize over both metal and ligand forming $\pi-d$ systems. In the case of $\mathrm{Cu}$, we observe a unique formation of $\mathrm{Cu}_{2} \mathrm{QDI}$ wires based on antiaromatic 12-membered macrocycles incorporating two metal centers, chemically connected by two C$\mathrm{C}$ single bonds but electronically independent (no conjugation between the macrocycles), preventing a full delocalization over the wire. We anticipate that the electronic delocalization together with the possibility to incorporate different transition metals provides new route to design $\pi-d$ polymers of desired magnetic and electronic properties. The on-surface synthesis under UHV conditions provides a unique possibility to further investigate magnetic and electronic properties of individual polymers by means of scanning probe microscopy. ${ }^{[67]}$

\section{Acknowledgements}

This was supported by GACR Expro 20-13692X. P.J. acknowledges support of the Czech Academy of Sciences through Praemium Academiae award. Ch.W. gratefully acknowledges financial support by the University of Zürich research priority program LightChEC and by the Swiss National Foundation (grant No. P300P2_177755). O.S. thanks the Centre National de la Recherche Scientifique, the Ministère de l'Enseignement Supérieur, de la Recherche et de l'Innovation. We acknowledge CzechNanoLab Research Infrastructure supported by MEYS CR (LM2018110). Computational resources were provided by the CESNET LM2015042 and the CERIT Scientific Cloud LM2015085, provided under the programme "Projects of Large Research, Development, and Innovations Infrastructures". P.L. acknowledges the support of the Ministry of Education, Youth and Sports of the Czech Republic under Project No. L01305, the Operational Programme for Research, Development and Education of the European Regional Development Fund (Project No. CZ.02.1.01/0.0/0.0/16_019/0000754).

Keywords: coordination modes $\cdot$ diamino-benzoquinonediimine - macrocycle $\bullet \pi$-d conjugation $\cdot$ scanning probe microscopy

[1] J. Weber, P.C. Beard, S.E. Bohndiek. Nature Methods 2016, 13, 639. [2] G. Qian, Z. Y. Wang. Chem. Asian J. 2010, 5, 1006.

[3] M. Stępień, E. Gońka, M. Żyła, N. Sprutta. Chem. Rev. 2017, 117, 3479.

[4] Electronic Materials: The Oligomer Approach (Eds.: K. Müllen, G. Wegner), Wiley-VCH, Weinheim, 1998.

[5] J. P.Llinas, A. Fairbrother, G. B. Barin, W. Shi, K. Lee, S. Wu, B. Y. Choi, R. Braganza, J. Lear, N. Kau, W. Choi, C. Chen, Z. Pedramrazi, T. Dumslaff, A. Narita, X. Feng, K. Müllen, F. Fischer, A. Zettl, P. Ruffieux, E. Yablonovitch, M. Crommie, R. Fasel, J. Bokor. Nat. Commun. 2017, 8, 633 .

[6] W.Niu, J. Liu, Y.Mai, K. Mullen, X.Feng. Trends in Chemistry 2019, 1, 549

[7] J. Cai, P. Ruffieux, R. Jaafar, M. Bieri, T. Braun, S. Blankenburg, M. Muoth, A. P. Seitsonen, M. Saleh, X. Feng. Nature 2010, 466, 470.

[8] A. Sánchez-Grande, B. de la Torre, J. Santos, B. Cirera, K. Lauwaet, T. Chutora, S. Edalatmanesh, P. Mutombo, J. Rosen, R. Zbořil, R. Miranda, J. Bjork, P. Jelínek, N. Martín, D. Ecija. Angew. Chem. Int 2019, 58, 6559.

[9] A. Shchyrba, C. Wäckerlin, J. Nowakowski, S. Nowakowska, J. Björk, S. Fatayer, J. Girovsky, T. Nijs, S. C. Martens, A. Kleibert. J. Am. Chem. Soc. 2014, 136, 9355.

[10] F. Huttmann, N. Schleheck, N. Atodiresei, T. Michely. J. Am. Chem. Soc. 2017, 139, 9895.

[11] D. Skomski, C. D. Tempas, G. S. Bukowski, K. A. Smith, S. L. Tait. J. Chem. Phys. 2015, 142, 101913.

[12] M. Koudia, E. Nardi, O. Siri, M. Abel. Nano Res. 2017, 10, 933.

[13] M. Telychko J. Su, A. Gallardo Y. Gu, J. I. Mendieta, D. Qi, A. Tadich, Sh. Song, P. Lyu, Zh. Qiu, H. Fang, M. Joo Koh, J. Wu, P. Jelínek, J. Lu. Angew. Chem. Int. Ed. 2019, 58, 18591 
[14] C. Krull, M. Castelli, P. Hapala, D. Kumar, A. Tadich, M. Capsoni, M. T. Edmonds, J. Hellerstedt, S. A. Burke, P. Jelinek, A. Schiffrin. Nat. Commun. 2018, 9, 3211.

[15] H. Masui, A. B. P. Lever.Inorg. Chem. 1993, 32, 2199.

[16] R. A. Metcalfe, L. C. G. Vasconcellos, H. Mirza, D. W. Franco, A. B. P. Lever. J. Chem. Soc., Dalton Trans. 1999, 2653.

[17] H. Audi, Z. Chen, A. Charaf-Eddin, A. D’Aléo, G. Canard, D. Jacquemin, O. Siri. Chem. Commun. 2014, 50, 15140.

[18] O. Siri, P. Braunstein, M.-M. Rohmer, M. Bénard, R. Welter. J. Am. Chem. Soc. 2003, 125, 13793.

[19] S. Pascal, O. Siri. Coord. Chem. Rev. 2017, 350, 178

[20] H. Masui, A. B. P. Lever, E. S. Dodsworth. Inorg. Chem. 1993, 32 258.

[21] B. Sarkar, D. Schweinfurth, N. Deibel, F. Weisser. Coord. Chem. Rev. 2015, 293, 250

[22] D. Schweinfurth, M. M. Khusniyarov, D. Bubrin, S. Hohloch, C.-Y. Su, B. Sarkar. Inorg. Chem. 2013, 52, 10332.

[23] N. Deibel, M. G. Sommer, S. Hohloch, J. Schwann, D. Schweinfurth, F. Ehret, B. Sarkar. Organometallics 2014, 33, 4756.

[24] I.-R. Jeon, J. G. Park, D. J. Xiao, T. D. Harris. J. Am. Chem. Soc. 2013, 135, 16845.

[25] J. A. DeGayner, I.-R. Jeon, T. D. Harris. Chem. Sci. 2015, 6, 6639.

[26] K. Ohno, A. Nagasawa, T. Fujihara. Dalton Trans. 2015, 44, 368

[27] K. Ohno, T. Fujihara, A. Nagasawa. Polyhedron 2014, 81, 715.

[28] Y. Su, Y. Zhao, J. Gao, Q. Dong, B. Wu, X.-J. Yang. Inorg. Chem. 2012, 51, 5889 .

[29] O. Siri, P. Braunstein. Chem. Commun. 2000, 2223

[30] J. Taquet, O. Siri, P. Braunstein, R. Welter. Inorg. Chem. 2006, 45, 4668 .

[31] J. Rall, A. F. Stange, K. Hübler, W. Kaim. Angew. Chem. Int. Ed. 1998 $37,2681$.

[32] S. Frantz, J. Rall, I. Hartenbach, T. Schleid, S. Záliš, W. Kaim. Chem. Eur. J. 2004, 10, 149.

[33] P. Braunstein, A. Demessence, O. Siri, J.-P. Taquet. Comptes Rendus Chim. 2004, 7, 909.

[34] O. Siri, J. Taquet, J.-P. Collin, M.-M. Rohmer, M. Bénard, P. Braunstein. Chem. - Eur. J. 2005, 11, 7247.

[35] H. Masui, A. L. Freda, M. C. Zerner and A. B. P. Lever. Inorg. Chem 2000, 39, 141.

[36] K. Biradha, A. Ramanan, J. J. Vittal. Cryst. Growth Des. 2009, 9,2969.

[37] K. Wada, K. Sakaushi, S. Sasaki, H. Nishihara. Angew. Chem. Int. Ed. 2018, 57, 8886

[38] K. Wada, K. Sakaushi, S. Sasaki, H. Nishihara. Angew. Chem. 2018, $130,9024$.

[39] J. Park, M. Lee, D. Feng, Z. Huang, A. C. Hinckley, A.Yakovenko,X. Zou, Y. Cui, Z. Bao. J. Am. Chem. Soc. 2018, 140, 10315.

[40] X. Huang, S. Zhang, L. Liu, L. Yu, G. Chen, W. Xu, D. Zhu. Angew. Chem. Int. Ed. 2018, 57,146.

[41] X. Huang, S. Zhang, L. Liu, L. Yu, G. Chen, W. Xu, D. Zhu, Angew. Chem. 2018, 130,152.

[42] Y. Chen, M. Tang, Y. Wu, X. Su, X. Li, S. Xu, S. Zhuo, J. Ma, D. Yuan, C. Wang, W. Hu. Angew. Chem. Int. Ed. 2019, 58, 14731.

[43] X.-F. Cheng, E.-B. Shi, X. Hou, J. Shu, J. He, H. Li, Q.-F. Xu,N.-J. Li, D. Chen, J.-M. Lu, Adv. Electron. Mater. 2017, 1700107

[44] S. Clair, D. G. de Oteyza. Chemical Rev. 2019,119, 4717.

[45] S.Zheng, Z. Chu, K. H. Lee, Q. Lin, Y. Li, G. He, J. Chen, G. Jia, Chem Plus Chem 2019, 84, 85 .

[46] C. Meseguer, S. Titos-Padilla, M. M. Hänninen, R. Navarrete, A. J. Mota, M. Evangelisti, J. Ruiz, E. Colacio, Inorg. Chem. 2014, 53 12092.

[47] P. Jelínek. J. Phys.-Condens. Mat. 2017, 29, 343002.

[48] L.Gross, F. Mohn, N. Moll, P. Liljeroth, G. Meyer. Science 2009, 325, 1110

[49] S. Dähne, D. Leupold. Coupling principles in organic dyes Angew. Chem. Int. Ed. Engl. 1966, 5, 984.

[50] V. Blum, R. Gehrke, F. Hanke, P. Havu, V. Havu, X. Ren, K. Reuter, M. Scheffler. Comput. Phys. Commun. 2009, 180, 2175.

[51] A.D. Becke. J. Chem. Phys. 1993, 98, 1372-1377.

[52] P. Hapala, G. Kichin, C. Wagner, F. S. Tautz, R. Temirov, P. Jelínek. Phys. Rev. B 2014, 90, 085421.

[53] M. Bieri, M.-T. Nguyen, O. Gröning, J. Cai, M. Treier, K. Aït-Mansour, P. Ruffieux, C. A. Pignedoli, D. Passerone, M. Kastler. J. Am. Chem. Soc. 2010, 132, 16669

[54] K.-H. Meiwes-Broer, Metal Clusters at Surfaces, Springer Berlin Heidelberg, Berlin, Heidelberg, 2000.

[55] J. Moulder, Handbook of X-Ray Photoelectron Spectroscopy: A Reference Book of Standard Spectra for Identification and Interpretation of XPS Data, Physical Electronics Division PerkinElmer Corp., Eden Prairie Minn., 1992.

[56] A. Rieger, S. Schnidrig, B. Probst, K.-H. Ernst, C. Wäckerlin, J. Phys. Chem. Lett. 2017, 8, 6193.

[57] Y. Bai, F. Buchner, I. Kellner, M. Schmid, F. Vollnhals, H.-P. Steinrück, H. Marbach, J. Michael Gottfried, New J. Phys. 2009, 11, 125004.

[58] W. Hieringer, K. Flechtner, A. Kretschmann, K. Seufert, W. Auwärter, J. V. Barth, A. Görling, H-P. Steinrück, and J. M. Gottfried, J. Am. Chem. Soc. 2011, 133, 6206.
[59] M. Chen, X. Feng, L. Zhang, H. Ju, Q. Xu, J. Zhu, J. M. Gottfried, K. Ibrahim, H. Qian, J. Wang, J. Phys. Chem. C 2010, 114, 9908.

[60] B. Li, T. He, Y. Fan, X. Yuan, H. Qiuaband, S. Yin. Chem. Commun. 2019, 55, 8036.

[61] P. V. R. Schleyer, C. Maerker, A. Dransfeld, H. Jiao, N. J. R. EikemaHommes. J. Am. Chem. Soc. 1996, 118, 6317.

[62] D. Geuenich, K. Hess, F. K.hler, R. Herges. Chem. Rev. 2005,105, 3758.

[63] M. Mauksch, S. B. Tsogoeva. Chem. Eur. J. 2018, 24, 10059

[64] H.S.Rzepa. Chem. Rev. 2005, 105, 3697.

[65] D. W. Szczepanik, M. Solà. Chemistry Open 2019, 8, 219.

[66] T. M. Krygowski, M. K. Cyrański. Chem. Rev. 2001, 101, 1385.

[67] L. Lafferentz, F.Ample, H. Yu, S. Hecht, C.Joachim, L.Grill. Science 2009, 323, 1193. 


\section{Entry for the Table of Contents}

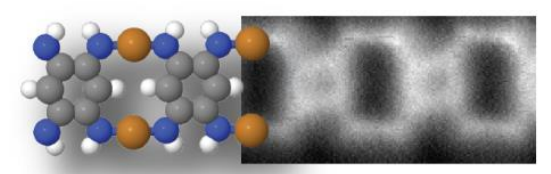

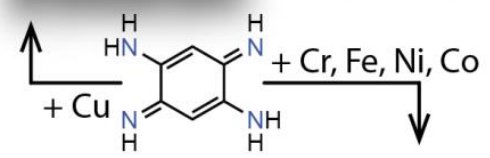

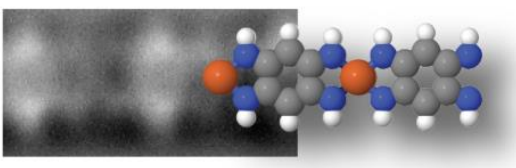

The on surface synthesis approach under UHV conditions has led us to the formation of 1D coordination m-d conjugated polymers on metal surfaces. The reaction of quinoidal ligand with different transition metals results in two distinct coordination motifs: four fold (Cr, $\mathrm{Fe}, \mathrm{Co}, \mathrm{Ni}$ ) and two fold $(\mathrm{Cu})$. The backbone of $\mathrm{Cu}$-coordinated 1D chain is formed by antiaromatic 12-membered macrocycles. 